\title{
Influência de um objeto de aprendizagem nas concepções de estudantes do ensino médio sobre ebulição da água
}

\author{
Maxwell Parrela Andreu - UFMS - maxparrela@ gmail.com \\ Maria Celina Piazza Recena - UFMS - mcrecena@ nin.ufms.br
}

Resumo: Foi desenvolvido um objeto de aprendizagem apresentando uma animação do processo de ebulição da água em nível microscópico. Este artigo relata a pesquisa realizada para verificar a influência de sua utilização, como mediador da discussão sobre as concepções de alunos do ensino médio, sobre esse processo. Observou-se uma evolução dos conceitos expressos pelos alunos nos sentidos dos modelos consensuais, principalmente em relação aos que apresentaram uma representação microscópica do fenômeno.

Palavras-chaves: concepções, objetos de aprendizagem, ebulição da água, química

Title: Influence of a virtual learning object in the conceptions of students in high school on boiling water

Abstract: It was developed a learning object presenting an animation of the process of boiling water into microscopic level. This article reports the survey to check the influence of their use as moderator of the discussion about the conceptions of High School students, about this process. There was an evolution of the concepts expressed by the students in the way of consensus models, mainly in relation to that presented a microscopic representation of the phenomenon.

Keywords: conceptions, learning objects boiling water, chemistry

\section{Introdução}

O conhecimento químico envolve três diferentes níveis de abordagem: macroscópico, microscópico e simbólico (Johnstone, 1982; Wu et. al., 2001). O nível macroscópico refere-se a fenômenos observáveis, o microscópico às explicações a nível de moléculas, átomos e o simbólico às representações de átomos, moléculas e compostos, como símbolos químicos, fórmulas e estruturas.

Freqüentemente, estudantes do ensino médio apresentam dificuldades na compreensão dos fenômenos físicos e químicos nos níveis microscópico e simbólico. Isso ocorre devido ao nível de abstração que envolve tais ciências e ao fato dos pensamentos destes alunos serem essencialmente baseados em informações sensoriais (Lin et al, citado por Balen e Netz, 2005; Wu et. al., 2001). "Se o (a) aluno (a) não souber como explicar à química utilizando-se de ferramentas ideacionais no nível microscópico, ele (a) efetivamente não aprendeu química". (Nakhleh citado por Rosa e Schnetzler, 1998).

Estudos mostram que alunos de diversas faixas etárias apresentam concepções sobre fenômenos, diferentes daquelas aceitas cientificamente (Beltran, 1997; Rosa e Schnetzler, 1998; Mortimer e Miranda, 1995).

Essas elaborações mentais são construídas à medida que o indivíduo se situa no mundo em que vive, ou seja, são resultados de suas experiências do cotidiano (Lin et al citados por Balen e Netz, 2005). As dificuldades de compreensão dos fenômenos, principalmente no nível microscópico, levam os alunos a apresentarem concepções diversas das aceitas pela comunidade científica. 
Para o professor, é importante conhecer as concepções dos alunos, para desenvolver um processo de ensino que proporcione condições de evolução das mesmas.

Visando propiciar a evolução das concepções dos estudantes, novas metodologias têm sido empregadas no âmbito educacional. $\mathrm{O}$ uso da informática neste processo tem se destacado. Esquembre citado por Balen e Netz (2005) aponta o uso de ferramentas de modelagem e simulação computacional como auxilio aos estudantes na compreensão e aprendizagem dos conceitos que descrevem os processos físicos e químicos, pois permite que explorem os modelos propostos e ressalta que o detalhamento microscópico e simbólico dos modelos é facilitado com tais ferramentas.

Neste sentido, ressalta-se a utilização de Objetos de Aprendizagem (OA) considerados segundo o grupo Learning Objects Metadata Workgroup do Institute of Electrical and Electonics Engineers (IEEE) e citado por Oliveira e Medina (2007) como "qualquer entidade, digital ou não digital, que possa ser utilizada, reutilizada ou referenciada durante o aprendizado suportado por tecnologias".

Os autores ressaltam que os OA podem ser usados individualmente pelos alunos ou coletivamente com uma turma, sendo um complemento para as atividades ou elaboração completa de uma aula.

Assim, elaboramos um objeto de aprendizagem que foi utilizado coletivamente com uma turma de alunos complementando a discussão sobre o tópico forças intermoleculares. O OA pode ser utilizado para outras discussões em contextos diferentes.

O processo de ebulição da água foi enfocado porque sua compreensão articula diversos conceitos importantes no entendimento de fenômenos químicos.

Sobre as idéias de estudantes relacionadas a fenômenos como a ebulição da água, Beltran (1997) observou, analisando representações pictóricas, algumas concepções que freqüientemente são usadas por eles: idéias de simultaneidade e não conservação de massa. Também Osborne e Cosgrove (1983), estudando as concepções de crianças e adolescente sobre mudanças de estado da água, verificaram que os estudantes tinham idéias diferentes das científicas. Inclusive constataram que adolescentes acreditavam que a água separava-se em hidrogênio e oxigênio no processo de ebulição.

Esses resultados foram confirmados em estudo, por nós realizado, com dezesseis alunos do segundo ano do ensino médio. Solicitamos que representassem pictoricamente a ebulição da água em quatro estágios. Para o desenho das moléculas foi sugerido o modelo de bolas e identificamos três concepções preponderantes entre eles: não conservação da massa no processo, simultaneidade (as moléculas de água simultaneamente mudam de estado físico) e mudança na constituição da molécula de água. (Andreu e Recena, 2006).

Este artigo relata a pesquisa realizada para verificar a influência da utilização do objeto de aprendizagem sobre ebulição da água, nas concepções dos estudantes sobre esse fenômeno.

\section{Metodologia}

A pesquisa foi desenvolvida em três etapas com onze alunos do terceiro ano do ensino médio de uma escola pública de Campo Grande: estudo das concepções dos estudantes em nível microscópico sobre o fenômeno da ebulição da água, apresentação e discussão da animação computacional e identificação de mudanças nas concepções inicialmente apresentadas pelos estudantes. 
- Estudo das concepções dos estudantes em nível microscópico sobre o fenômeno da ebulição da água

As concepções iniciais dos alunos foram estudadas com base em duas questões. A primeira apresentava cinco alternativas de representações em nível microscópico da ebulição da água, usando o modelo de bolas para representar as moléculas. Uma das cinco opções é a considerada aceita cientificamente, as quatro restantes, expressam uma concepção identificada no estudo anterior, realizado pelos pesquisadores com alunos da mesma escola, série escolar e faixa etária. (Andreu e Recena, 2006).

Cada alternativa era composta por três estágios de evolução do fenômeno, tal como a seguir:

A alternativa "a" representava a idéia de simultaneidade. Numa primeira situação a água esta no estado líquido, numa segunda etapa todas as moléculas passaram simultaneamente (de uma só vez) para o estado de vapor.

A alternativa " $b$ " representava a não conservação da massa. As moléculas mudam de fase gradativamente, mas o número de entidades não permanece constante.

A alternativa "c" representava a cientificamente aceita.

A alternativa "d" representava uma mistura de níveis representacionais onde temos no estado liquido as moléculas de água representas e na fase vapor é mostrado "fumacinhas".

A alternativa "e" representava a mudança estrutural da molécula de água representando o fenômeno como sendo uma decomposição da água em hidrogênio e oxigênio.

Caso o aluno não se identificasse com nenhuma alternativa, poderia representar sua idéia construindo sua própria alternativa.

Também foi proposta uma segunda questão onde deveria ser marcada uma ou mais alternativas que correspondesse ao conceito formal do processo de ebulição. Esta questão foi colocada com o propósito de avaliar a concordância das concepções dos estudantes apresentadas pelas escolhas das representações pictóricas com o conceito formal para o fenômeno em estudo. Nesta questão foram adicionadas propositalmente algumas alternativas que concordassem com prováveis respostas obtidas na questão anterior.

- Apresentação e discussão do objeto de aprendizagem

Em duas aulas seguidas, totalizando 90 minutos, foi apresentada a animação representando a ebulição da água em nível microscópico. O professor (um dos autores) discutiu com os alunos suas concepções evidenciando aproximações e afastamentos do modelo científico.

- Identificação de mudanças nas concepções inicialmente apresentadas pelos estudantes.

Após a atividade com a animação, os alunos foram convidados a rever suas respostas iniciais ao questionário e indicarem mudanças justificando-as.

\section{Construção da animação}

A animação foi construída utilizando o software Macromedia Flash Professional MX 2004 versão demo. No site $^{1}$ do fabricante pode ser adquirida a versão de demonstração mais recente que expira em 30 dias. O flash é uma ferramenta largamente utilizada na produção de animações para a internet, e possui a vantagem de ser multiplataforma. $\mathrm{Na}$ animação são mostradas as moléculas em movimento na mudança de fase.

Para o desenho das moléculas de água (modelo de bolas) e o sistema de ebulição foi utilizado o software ACD/ChemSketch 8. Este software é uma ferramenta muito útil para desenhos em química e pode ser adquirida a versão freeware (gratuita) que não 
perderá suas funcionalidades, no $\operatorname{site}^{2}$ da ACD/LABS. Depois de desenhadas as moléculas foram exportadas no formato de imagem bitmap (.bmp).

No flash foram inseridas as moléculas de água obtidas no ChemSketch e a estas foram atribuídos movimentos de rotação e translação, imitando o modelo cinético aceito para o fenômeno ebulição da água. Depois de terminada, a animação (figura 1) foi salva no formato de animações do flash (.swf). Dessa forma ela poderia ser visualizada em qualquer navegador de internet (Internet Explorer, Netscape, Mozilla, Firefox, Opera, etc.) com o plug-in ${ }^{3}$ do flash instalado.

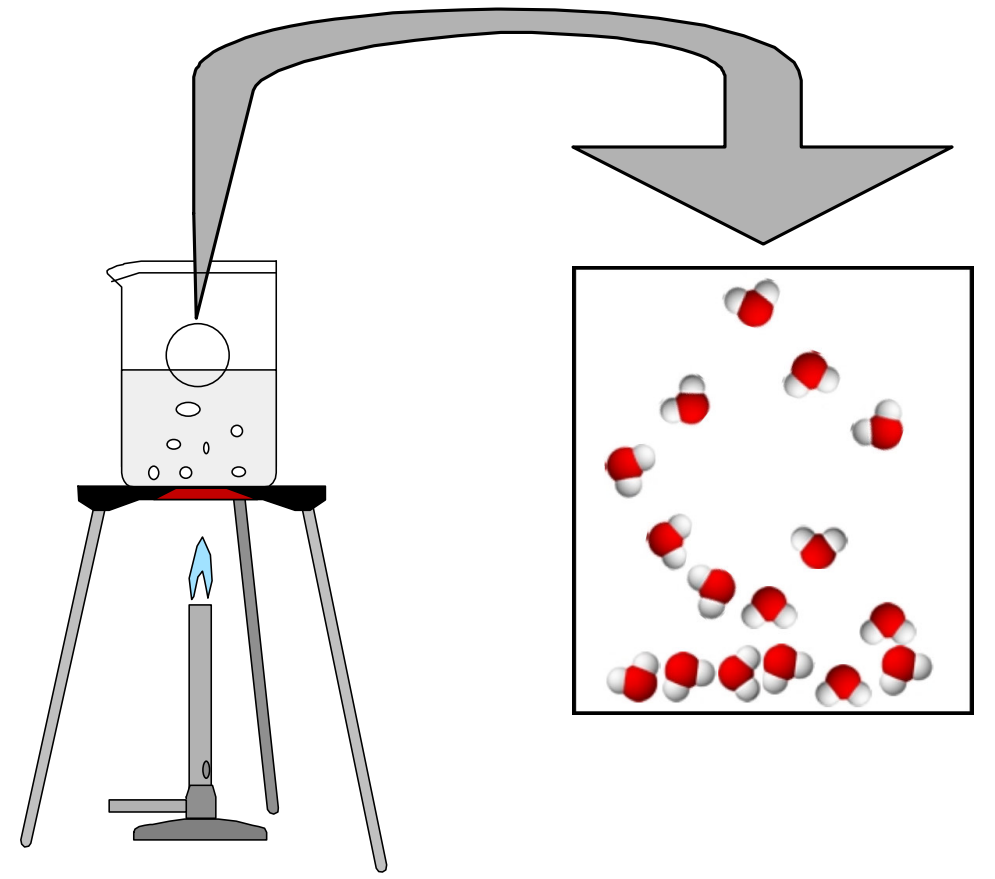

Figura 1: Sistema em ebulição e tela da animação em flash

\section{Resultados e discussão}

Com o objetivo de verificar a influencia do OA na evolução das concepções dos alunos, tendo como base as alternativas da primeira questão do questionário inicial, agrupou-se as respostas em dois grandes grupos:

Grupo A - As moléculas de água são identificadas microscopicamente na fase vapor.

Grupo B - As moléculas de água não são identificadas microscopicamente na fase vapor.

O grupo A é representado pelas alternativas a, b e c. que apesar de possuírem significados diferentes, nelas as moléculas de água são mostradas explicitamente na fase vapor.

O grupo B é representado pelas alternativas "d" e "e" onde as moléculas de água não são mostradas na fase vapor. Na alternativa "d" que contempla uma mistura de níveis representacionais, não se vê as moléculas na fase vapor e sim "fumacinhas". A alternativa "e" deixa de forma clara a idéia de reação, especificamente de decomposição da água em hidrogênio e oxigênio.

Relacionando as alternativas da primeira questão do questionário inicial, foram criados os cinco subgrupos $\mathrm{Aa}, \mathrm{Ab}, \mathrm{Ac}, \mathrm{Bd}$ e $\mathrm{Be}$, com as seguintes características: 
Aa - As moléculas de água são identificadas microscopicamente na fase vapor e idéia de simultaneidade. O único caso para este subgrupo foi Ângela ${ }^{4}$. No questionário inicial ela relatou que: “... o processo ocorre de maneira uniforme (de uma só vez)...”.

$\mathrm{Ab}$ - As moléculas de água são identificadas microscopicamente na fase vapor e idéia de não conservação da massa.

Ac - As moléculas de água são identificadas microscopicamente na fase vapor, a ebulição ocorre gradativamente, o número de moléculas permanece constante durante o processo, subcategoria que representa o que é aceito cientificamente para o fenômeno em questão.

Bd - As moléculas de água não são identificadas microscopicamente na fase vapor e não identificação de qualquer espécie. Nesse caso o vapor simplesmente é representado por "fumacinhas". Os alunos Daniel, Maria, Marcelo, Raquel e Kelly foram classificados nesse subgrupo. Raquel na justificativa da sua escolha diz: "porque a fig. d mostra o processo de evaporação". Para a mesma questão Marcelo justifica que "com o aquecimento ela evapora...”.

Be - As moléculas de água não são identificadas microscopicamente na fase vapor e o processo de ebulição é caracterizado aqui por uma decomposição das moléculas de água em hidrogênio e oxigênio. Corresponde a este subgrupo Antonio, Eduardo, Gisele, Lauren e Janaina. Eduardo ao justifica sua escolha diz: “... ela está começando a borbulhar, ou seja, oxigênio livre começa a subir soltando-se do hidrogênio... mostrando a divisão da molécula de água...". Lauren justifica que escolheu da alternativa "e" porque ela esta "... mostrando as moléculas de oxigênio se separando das de hidrogênio".

\begin{tabular}{|c|c|c|c|c|}
\hline Aluno & $\begin{array}{c}\text { Pesquisa } \\
\text { Inicial }\end{array}$ & $\begin{array}{c}\text { Pós } \\
\text { teste }\end{array}$ & Evolução & Observações \\
\hline Antonio & Be & Ac & $\begin{array}{c}\text { Reconhecimento } \\
\text { microscópico das moléculas } \\
\text { de água na fase vapor e } \\
\text { evolução quanto à idéia de } \\
\text { decomposição. }\end{array}$ & $\begin{array}{c}\text { Apresenta o conceito formal } \\
\text { na pesquisa de concepções. }\end{array}$ \\
\hline Ângela & Aa & Ac & $\begin{array}{c}\text { Quanto à idéia de } \\
\text { simultaneidade no fenômeno } \\
\text { de ebulição da água, } \\
\text { reconhecimento de que o } \\
\text { processo é gradativo. }\end{array}$ & $\begin{array}{l}\text { Apresenta o conceito formal } \\
\text { na pesquisa de concepções. }\end{array}$ \\
\hline Eduardo & Be & Ac & $\begin{array}{c}\text { Reconhecimento } \\
\text { microscópico das moléculas } \\
\text { de água na fase vapor e } \\
\text { evolução quanto à idéia de } \\
\text { decomposição. }\end{array}$ & $\begin{array}{c}\text { Apresenta o conceito formal } \\
\text { na pesquisa de concepções. }\end{array}$ \\
\hline Gisele & Be & Ac & $\begin{array}{c}\text { Reconhecimento } \\
\text { microscópico das moléculas } \\
\text { de água na fase vapor e } \\
\text { evolução quanto à idéia de } \\
\text { decomposição. }\end{array}$ & $\begin{array}{c}\text { Apresenta o conceito formal } \\
\text { na pesquisa de concepções. }\end{array}$ \\
\hline Be & Ac & $\begin{array}{c}\text { Reconhecimento } \\
\text { microscópico das moléculas } \\
\text { de água na fase vapor e } \\
\text { evolução quanto à idéia de }\end{array}$ & $\begin{array}{c}\text { Não apresenta o conceito } \\
\text { formal na pesquisa de } \\
\text { concepções. }\end{array}$ \\
\hline
\end{tabular}




\begin{tabular}{|c|c|c|c|c|}
\hline \multirow{3}{*}{$\begin{array}{c}-0 \\
\\
\text { Maria }\end{array}$} & \multicolumn{2}{|c|}{ CINTED-UFRGS } & \multicolumn{2}{|c|}{ Novas Tecnologias na Educação } \\
\hline & & & decomposição. & \\
\hline & $\mathrm{Bd}$ & Ac & $\begin{array}{c}\text { Reconhecimento } \\
\text { microscópico das moléculas } \\
\text { de água na fase vapor, } \\
\text { compreende que as } \\
\text { "fumacinhas" são formadas } \\
\text { por moléculas de água. }\end{array}$ & $\begin{array}{c}\text { Apesar de marcar a } \\
\text { alternativa correta não } \\
\text { utiliza de argumentos que } \\
\text { justifiquem sua escolha. } \\
\text { Apresenta o conceito formal } \\
\text { na pesquisa de concepções. }\end{array}$ \\
\hline Raquel & $\mathrm{Bd}$ & Ac & $\begin{array}{c}\text { Reconhecimento } \\
\text { microscópico das moléculas } \\
\text { de água na fase vapor, } \\
\text { compreende que as } \\
\text { "fumacinhas" são formadas } \\
\text { por moléculas de água. }\end{array}$ & $\begin{array}{c}\text { Utiliza de poucos } \\
\text { argumentos para justificar } \\
\text { sua escolha. Apresenta o } \\
\text { conceito formal na pesquisa } \\
\text { de concepções. }\end{array}$ \\
\hline Daniel & $\mathrm{Bd}$ & Ac & $\begin{array}{c}\text { Reconhecimento } \\
\text { microscópico das moléculas } \\
\text { de água na fase vapor, } \\
\text { compreende que as } \\
\text { "fumacinhas" são formadas } \\
\text { por moléculas de água. }\end{array}$ & $\begin{array}{l}\text { Argumentos utilizados não } \\
\text { justificam sua escolha. Não } \\
\text { apresenta o conceito formal } \\
\text { na pesquisa de concepções. }\end{array}$ \\
\hline Janaina & $\mathrm{Be}$ & $\mathrm{Be}$ & Não houve evolução & $\begin{array}{l}\text { Apresenta o conceito formal } \\
\text { na pesquisa de concepções. }\end{array}$ \\
\hline Kelly & $\mathrm{Bd}$ & $\mathrm{Bd}$ & Não houve evolução & $\begin{array}{l}\text { Apresenta o conceito formal } \\
\text { na pesquisa de concepções. }\end{array}$ \\
\hline Marcelo & $\mathrm{Bd}$ & Ac & $\begin{array}{c}\text { Reconhecimento } \\
\text { microscópico das moléculas } \\
\text { de água na fase vapor, } \\
\text { compreende que as } \\
\text { "fumacinhas" são formadas } \\
\text { por moléculas de água. }\end{array}$ & $\begin{array}{l}\text { Argumentos utilizados não } \\
\text { justificam sua escolha. } \\
\text { Apresenta o conceito formal } \\
\text { na pesquisa de concepções. }\end{array}$ \\
\hline
\end{tabular}

Tabela 1: Evolução conceitual dos alunos

\section{Conclusões}

Os alunos do ensino médio apresentaram concepções diferentes das aceitas cientificamente em relação ao processo de ebulição. Na pesquisa inicial das concepções, nenhum aluno indicou a maneira que melhor representa a ebulição da água.

A maioria (90\%) dos alunos não identificou as moléculas de água no vapor. Não indicaram (45\%) espécie alguma no nível microscópico (fumacinhas) ou indicaram a decomposição (45\%) da água em hidrogênio e oxigênio. Entretanto quase todos os alunos, exceto Daniel e Lauren, apresentaram o conceito formal. Isto pode ocorrer devido à adoção de métodos clássicos de ensino, com ênfase na definição do conceito e não no seu entendimento fenomenológico. O resultado é uma aprendizagem essencialmente mecânica.

A utilização do OA produziu evoluções conceituais, sendo a principal delas a identificação das moléculas de água no vapor. Os alunos que se enquadraram nas 
categorias "Be" e "Aa" foram os que apresentaram evoluções mais significativas, abandonando as idéias da decomposição da água e de simultaneidade respectivamente. Os alunos classificados como "Bd" embora escolhendo a alternativa correta, não apresentaram justificativas consistentes, sugerindo outras dificuldades além das constatadas. Observou-se nesse caso que grande parte dos alunos não apresentou compreensão em nível microscópico nem articularam os níveis micro e macroscópico. Os melhores resultados foram obtidos com os alunos que já possuíam algum domínio conceitual ou concebiam o fenômeno em nível microscópico, concordando com Santos e Greca (2005). Esse tipo de abordagem parece ser mais efetivo na consolidação de conceitos, e não como introdução aos mesmos.

Ressalta-se que o estudo apresenta limitações por devido à segunda aplicação do questionário ter sido imediata a discussão do OA, não sendo possível determinar se as mudanças observadas foram persistentes.

Como subsídio para a abordagem desse assunto em sala de aula ou situações pedagógicas sugere-se a retomada da discussão sobre transformações físicas e químicas da matéria, com ênfase na abordagem microscópica.

É importante ressaltar que materiais, como o OA produzido, não produzirão evolução conceitual por si próprio, sendo importante o planejamento, questionamentos em momentos propícios, dentre outras interferências pedagógicas.

\section{Notas}

$1 \mathrm{http}: / / \mathrm{www} \cdot$ adobe.com/br/downloads/

2 http://www.acdlabs.com/download/

3 http://www.adobe.com/shockwave/download/

4 Os nome utilizados são fictícios

\section{Referências bibliográficas}

ANDREU, M.P. e RECENA, M. C. P. Concepções de estudantes do ensino médio relacionadas à ebulição da água. In: $13^{\circ}$ ENCONTRO NACIONAL DE ENSINO DE QUÍMICA, 2006, Campinas. Anais. UNICAMP, 2006, p. 28,.

BALEN, O. e NETZ, P. A. Aplicação da modelagem e simulação no ensino de modelos de sistemas gasosos. Acta Scientiae 7(2). 29-39, 2005.

BELTRAN, N. O. Idéias em movimentos. Química Nova na Escola, 5, 14-17, 1997.

JOHNSTONE, A. Macro and Microchemistry. The School Science Review, v.64, n.227, 1982.

MORTIMER, E. F e MIRANDA, L. C. Transformações: concepções dos estudantes sobre reações químicas. Química nova na escola, 2, 23-26, 1995.

OLIVEIRA e MEDINA. Desenvolvimento de objetos de aprendizagem para dispositivos móveis: uma nova abordagem que contribui para a educação. Renote. 2007. Disponível em: < http://www.cinted.ufrgs.br/renote/jul2007/artigos/leandroramosdesenvolvimento.PDF>. Acesso em: 30/10/2007. 
OSBORNE, R. J. e COSGROVE, M. M. Children's Conceptions of the Changes of State of Water. Journal of Research in Science Teaching, 20(9), 825-838, 1983.

ROSA, M. I. de F. P. S e SCHNETZLER, R. P. Sobre a importância do conceito transformação química no processo de aquisição do conhecimento química. Química nova na escola, 8, 31-35, 1998.

SANTOS, F. M. T e GRECA, I. M. Promovendo aprendizagem de conceitos e de representações pictóricas em Químicas com uma ferramenta de simulação computacional. 2005. Revista Electrónica de Enseñanza de Las Ciencias, 4(1). Disponível em: < http://www.saum.uvigo.es/reec/volumenes/volumen4/ART7_Vol4_N1.pdf> Acesso em: 30/10/2007.

WU, KSIN-KAI, KRAJCIK, J.S. e SOLOWAY, E. Promoting Understanding of Chemical Representations: Students' use of a visualization tool in the classroom. [Eletronic version] Journal of Research in Science Teaching. 38(7), 821-840, 2001. 